\title{
Effects of Competency, Leadership and Team Integration Abilities of Project Managers on Success of Projects in Telecom Industry of Pakistan
}

\author{
Haris Ahmed Khan \\ Institute of Communication Technologies, Islamabad \\ (Affiliated with UET Peshawar) \\ Islamabad, Pakistan
}

\author{
Dr. Shahzada Alamgir Khan \\ Institute of Communication Technologies, Islamabad \\ (Affiliated with UET Peshawar) \\ Islamabad, Pakistan
}

\author{
Dr. Muhammad Umer \\ CASE, Islamabad \\ Islamabad, Pakistan
}

\begin{abstract}
The project success can be termed as attaining the project deliverables within designated budget and timelines, by satisfying the stakeholders while learning from experiences on the way. The success factors depend upon mission statement and strategic goals of a project. [1] Apart from many other reasons, the success of a project is widely reliant upon certain personality traits of a project manager like competency, leadership, integrity and team building abilities. These capabilities indirectly impact the growth of economy considering the vitality of these projects in telecom industry. This study explores the influence of such competencies of a project manager on accomplishment of projects in telecom industry of Pakistan.
\end{abstract}

A questionnaire including 61 independent questions regarding project success, manager competence, manager leadership and manager team integration abilities was adapted from previous studies. Data was collected from 295 professionals from various telecom operators and suppliers in Islamabad. The data was subjected to statistical tests including Pearson's correlation for the study of suggestive relationships among the dependent and independent variables and regression for impact study on multiple variables at the same time.

The outcomes of this study suggests that success of telecom projects in Pakistan are highly dependent on Competency, Leadership and Team Integration abilities of Project Managers. Furthermore, all the four independent variables are found to be interrelated to Project Success.

Keywords- Project success, Competency, Leadership, Integrity and Team Integration abilities of Project Managers

\section{INTRODUCTION}

\section{A. Study Background}

Success of Telecom projects in Pakistan are vital in the economic growth of the country and it's Telecom Industry. These projects, usually being supervised by a professional project manager, undergo unique challenges which demand effective and prompt communication with all the stakeholders. The project managers take responsibility and ensure that the directions are parallel with project requirements. The same project manager will have to follow the strict timelines being set in a competitive industry. The above mentioned traits of a project manager requires specific skills which will lead to successful delivery of Telecom projects. Considering a project type, the project managers need to be carefully selected for positive outcome of the project success parameters.

Success of Telecom projects in Pakistan are vital in the economic growth of the country and it's Telecom Industry. These projects, usually being supervised by a professional project manager, undergo unique challenges which demand effective and prompt communication with all the stakeholders. The project managers take responsibility and ensure that the directions are parallel with project requirements. The same project manager will have to follow the strict timelines being set in a competitive industry. The above mentioned traits of a project manager requires specific skills which will lead to successful delivery of Telecom projects. Considering a project type, the project managers need to be carefully selected for positive outcome of the project success parameters.

In developing countries like Pakistan, it faces many obstacles in its engineering projects in Telecom industry which requires skills such as highly competitive human resources, design knowledge, managerial capabilities and good leaders. The telecom investment as per PTA was more than 6000 million dollars in fiscal year 2016-2017. Based on these financial figures of huge local and foreign investment, a conclusion can be deduced that the Telecom Industry plays a vital part in economic backbone, not to mention its critical importance in communication requirements. It is important to assess and evaluate the effects of competency, leadership and team integration abilities of project managers on success of projects in telecom industry of Pakistan.

\section{B. Problem Statement}

The primary objective of this research remains to evaluate, assess and inspect the effects of project manager's abilities of competency, leadership, integrity and team integration on success of projects in telecom industry of Pakistan. 


\section{Research Objectives}

The focus of this study is on the following issues:

a. To explore degree of success for telecom projects in Pakistan.

b. To assess the attitude of telecom employees towards project team integration.

c. To evaluate the relationship of manager competency, manager leadership, integrity and team integration abilities with project success in telecom industry of Pakistan.

d. To provide guidelines to telecom industry in shaping up the requirements for a better and effective project management.

\section{Research Questions}

1. Does manager competency in Pakistan Telecom sector have positive impact on project success?

2. Is manager Leadership a determining factor in success of telecom projects in Pakistan?

3. Does the placement of manager's team integration abilities affect the project team to better achieve the project goals?

4. Is there a positive influence of project manager's integrity on success of projects?

5. Is there is a possibility that all above mentioned traits in a manager have a combined effect on project success in Telecom industry of Pakistan.

\section{E. Significance of the Study}

There is dearth of exploration and research in Pakistan on project management, especially with respect to the telecom project success. The study shall be a significant contribution in exploring the factors which affect the project success with respect to the telecom industry in Pakistan and in ways it can be improve this success for a prosperous telecom industry. The research also aim to help in developing guiding principles for the human resource faction of telecom industry so as to efficiently manage the workforce present in the project management and delivery teams. The study intends to provide vital insight with respect to the requirements that a project manager needs to possess in terms of Integrity, Leadership Qualities and Team Building Abilities.

\section{FRAME WORK AND LITERATURE REVIEW}

\section{A. Literature Review}

Project Success: A project can only be successful if the success criteria were defined upfront. Employing an able and competent project manager is the primary footstep to materialize the success of any project. However, further important factors also affect the project's outcome greatly. In order to successfully complete a project, it takes meticulous planning and active communication along with a slight attention to detail. Earlier researches have defined the project success based on perceptions. Therefore, if some certain requirements are fulfilled then perception guides whether the project was successful or not. These requirements are but not limited to mission, performance, satisfaction of internal and external stake holders along with harmony among team members. Factors related to project time and project cost may not be enough to single handedly speculate on success of the projects. None the less these are important factors which govern the projects related to IT and Telecom. Specifications, practical goals and technical performance are some of the parameters which in conjunction with quality are seemingly different for varying type of project participants. [17]

Success Criterion \& Factors for Project Success: For a job or role, success is extremely important. It can be explained in diverse factors like goal, trait, knowledge and personal characteristics etc. In order to evaluate the achievement or purpose by a manager, a requirement arises to define the factors for critical success. For any important activity, the critical success factors will determine the requirement and direction of favorable results as essentially required by a manager [1]. In another definition, critical success factors (CSFs) have mostly being linked to the mission and vital objectives of any project, whereas what is to be achieved relates to the mission and primary objectives. Critical Success Factors center around the most essential zones and gives vital insight on what is to be achieved and how it can be achieved. [2] Success factors and success criteria are both different from each other and it's important to clearly distinguish between the two. The criteria for success can be defined as those procedures which may evaluate the success or failure of any project. Moreover, the factors affecting the project management in any direction can be termed as critical success factors. [3]

In project management domain, a very valuable and important issue is the project's success [4]. Even though, it's a frequently debated issue but consensus regarding the best criteria for a project's success is yet to be achieved. [5] Many researchers have suggested that there are two different categories of factors namely specific factors and general factors. A set of unique critical success factors was identified for varying objectives of projects. [6] The application of CSFs are limited but they highly contribute to the project success in all aspects. For that reason, it is not a simple task to identify and correlate the CSFs with project success considering the project objectives and complications involved.

Project Managers' Competency Profile: A successful industry requires a combination of certain features behind its success. [7] Good leaders dedicated to their vision are a key ingredient to these success features. A responsible and competent manager must take responsibility of his actions then combine the involved people together to achieve a certain goal. Being a people manager requires motivating the team on a regular basis. A certain balance needs to be maintained by a good manager for diverse areas like manpower, quality, expenses, time, scope of work and risks. Many different processes including initiating of a project, planning of a project, executing a project, monitoring of a project, controlling of a project and finally closing of a project are also important areas where a manager's diligence is much needed. [8]

Behind every successful project there is always a responsible project manager. A smooth relationship between management leadership and project managers is extremely crucial for the attainment of any project as dictated by principles of project management. The complexities and stages of projects require the project managers to be duly 
competent in its respective role. [9] Project success is widely impacted by diverse characteristics of project managers. A manager should be carefully selected by identifying the nature of the project and its type. [10] A project manager may apply his knowledge and skills along with proven techniques and supportive tools to achieve project success. [11] PMCS (Project Management Control System) defines that the project managers may apply the best practices which can be helpful to increase the project success. The project managers can also apply their expertise to effectively fulfill the requirements of different stakeholders.

Project Management Competency: Competence or competency is derived from "Competentia" which is a Latin word. Competence refers to the capability to perform a given task both efficiently and successfully. [12] The terms 'competent' or 'competence' or 'competency' are stated as a certain quality of being fit and performance capable. [13] As per PMCD Framework recommendations, competence can be defined as being ready to perform in a specific field which may lead to expected results dependent on specific principles. [4] Referring to a certain task in order to achieve completion and success, competence is an assortment of skills, approaches, practice, and knowledge. [12] As referred to Parry by Barna [11] and defines the competency as certain individual characteristics, skills, knowledge and attitude which is ...

- refined by training and development.

- related by specific performance at job

- calculated via well-recognized methodologies \&

- directly affecting the job outcome

According to IPMA, three varying ranges are employed in order to define competence w.r.t project management

- Behavior

- Technicality

- Context

The Institute of Project Management supported PMCD framework was established in year 2002 to deliver guidelines to establishments as well as single entities in order to accomplish and guide the development of project related managers. [14] It comprises of following dimensions:

1) Project manager's Personal competence: A manager's performance in diverse workplaces along with actions. Moreover morals and persona are also imperative.

2) Project Manager's Competence in terms of knowledge: A PM's understanding about the project, tools, processes and methods to conclude the project deliverables.

3) Performance Competence of Project Managers: The knowledge and competency being used by the PM to deliver successful project.

Personal competence along with performance competence evaluation of project manager will be the primary task for this research. PMCD framework defines the evidence type which will be used to assess the performance where an individual's competent performance is evident in each element. [14] In order to assess performance criteria, PMCD framework have defined many types of evidences which in turn help define the personal competence. Different associations like AIPM (Australian Institute of Project Management), APM (Association for Project Management) and IPMA (International Project Management Association), all have described PM competencies as per their own understanding and expertise on the subject. Frameworks supported by IMPA and PMCD (Project Manager Competence Development) are being employed for the purpose of research in assessment of competencies of different project managers. Diverse rudiments related to the overall complication of framework defining the terms of engagement were being mapped with prior capabilities for improvement in project delivery. [15].

Leadership Styles: Leadership styles are unique to every manager or every leader. Some of the managers are more supportive and open while others are very assertive. Leadership is categorized in into a wide range of leader styles like transformational, transaction, authoritarian, participative, democratic and lasses-faire are categorized. [34] The characteristics of a seasoned leader always bears creativity and motivation along with a fringe of entrepreneurship and commitment. A worthy leadership proves itself by ensuring that timelines are met for achieved goals so that the business growth is consistent with overall progress. Without good leadership it is very evident that management goals will not be met as efficiently as required. [34] For a more thorough management, proper setting of goals is required in order to lead the subordinates for achievement of organizational goals Based on circumstances, leadership styles are also variable and subject to change. [35]

An effective leadership balances the strategy towards a positive and fruitful project outcome. Such leadership practices include steering the project towards logical success by providing required administrative support. The strategic goals at this instance must be well versed by the managers and their respective subordinates. Geoghegan \& Dulewicz [36] state that if good managers can be termed as individuals who do tasks right then leaders can be termed as ones doing right thing. The leadership roles involves sharing of responsibilities among team members in a project as debated conventionally by many scholars. [36] However, in current project management literature, the managers' leadership role in contributing the success of the projects is still much debatable. By various articles, it is evident that management selection and performance of a project are interrelated. (Crawford et al., 2005; Dulewicz and Higgs, 2003). [4] [38] Jian 2014 concluded that the effective leadership is crucial to the accomplishment of any project. [39]

Team Integration: The project leader must foster an atmosphere which encourages mutual trust and confidence among team members. Thamhain emphasizes that, the effectiveness of a project leader in minimizing the barriers and stimulating the drivers improves the development of team membership and eventually contributes in higher quality of information. This includes their willingness, openness and sincerity in sharing novice ideas and methodologies. [16] An important point emphasized by a project leader: The most unfortunate thing would be to have a team having trust issues with each other. These circumstances lead to contests between different team members, all interested in self proclaim rather than project success. Moreover, rise of trust and unity among project team fosters an environment for team members to effectively develop decision making processes, concentrate on 
issue resolution, grow self-enticing \& correction focused on project principles and making individual as well as group commitment.

Views regarding effectiveness of team building are subject to remarkable diversity. As concluded by Shandler and Egan, with respect to implementing team integration within a group may transform the same group in a result delivering team. However, Salas 2009, claims that performance and team building are not interrelated in a more general analysis. [23] Despite varying kinds and existence of team building interferences, the response to team building interventions in relation to success in still inconclusive. Success is claimed by some, [24] while others like Wolff, Woodman \& Sherwood have pointed out the lack of relationship between success and teambuilding. [29] [30] Different types of outcomes regarding success of a project are being estimated. It comprises of different procedures (effective communications, management, judgement etc.), performance of the team (quantity, excellence $\&$ effectiveness etc.) and emotional conclusions (trust \& socialization etc.) Team building interventions can target many diverse goals that include cultivation of problem solving skills, trust improvement, enhancement of leadership skills, and refinement of proper communication. (Mazany, Francis, \& Sumich, 1995) [24] [37] More importantly there are activities which focus om group cohesion always builds encouragement of participants to solve common project issues as a group and share the responsibility. [31] [32] The concept of team integration primarily becomes, an effective intercession to enhance the organizational effectiveness by engaging in employee progress. Especially, if there are appropriate conditions in context to the organization and its teams. (Dyer [26]; De Meuse and Liebowitz [25]; Adair [27]; Woodcock [28]) In terms of management of projects, many factors narrate the overall capacity of manager to effectively deliver project objectives. [16] Being an important factor affecting the project success, the team integration role will also be explored in the research paper as an independent variable.

Integrity: One of the important factor as part of project manager's ability is honesty or integrity of a project manager. The definition of honesty as per Project Manager Institute (PMI) is responsibility to evaluate truth then perform in an honest way for both communication and behavior alike. The project manager role requires that a project manager is truthful, honest and transparent while declaring all the pertaining information to his/her peers and subordinates alike [42]. This particular personal proficiency of a project manager will contribute greatly to the effective conclusion of the projects.

Importance of integrity of a project manager is vital because it supports in selling the idea of success to the involved team members who look up to their superiors for guidance. Thus the team members actually adopts the whole idea of honesty and become an extension of the project manager in implementing this integrity in their respective work. This also helps to improve the project delivery. Therefore, a project manager must display integrity and honesty at all times to nurture an atmosphere of trust among team members and eventual customers. It is pertinent to follow the realistic project timelines without over committing. In some cases, the safety and security of team members in field depends upon the level of flexibility shown by a project manager towards tight schedules. Moreover, project managers also have to safeguard the stakeholder's interests by making sure that integrity and honesty are thoroughly reflected in the team attitude as well. [43] The team members in return have increased sense of security that their efforts are properly recognized and that the project manager will act in their best interest. Among other things, team members are influenced most by integrity based on two main features in a project manager, Impartiality and Thoroughness. Impartiality suggests that the project manager works without any prejudice or favoritism. And thoroughness is the skill of project manager to finish the tasks at hand completely and have a clear evaluation of each step of project administration. [44]

The PMI (Project Management Institute) code of ethics declare honesty or integrity as one of the important pillars of work ethics while dealing in project management. Further to it, honesty is a duty of a project manager so as to comprehend fact and perform in a truthful way for communication and conduct alike. These code of ethics bound the project managers all over the world to implement honesty and integrity among other requirements. Hence the analysis of this important trait with respect to project success is vital for this research and will benefit the overall analysis greatly.

\section{B. Research Hypothesis}

H1: Project Manager Competency relates to the project success positively.

H2: Project Manager Leadership impacts the project success positively.

H3: Team Integration abilities of project managers have a positive affect on project success.

H4: Manager Integrity influences the project success positively.

H5: Success of Projects in Telecom Industry of Pakistan are affected by Competency, Leadership and Team Integration abilities of Project Managers.

\section{Research Framework}

Following figure with independent and dependent variables relate to the research methodology of this project.

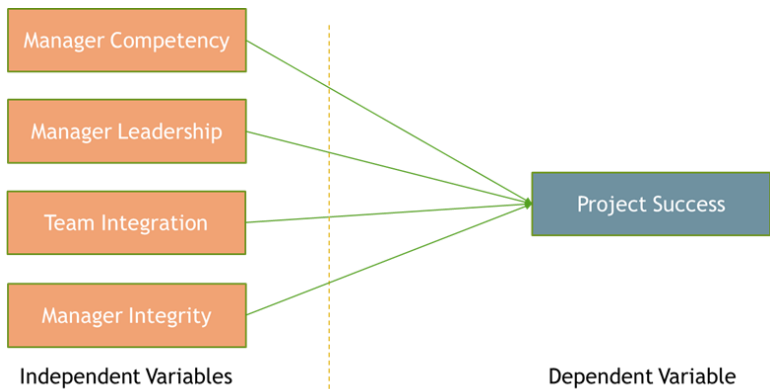

Fig. 1. Variables Relationship

The above methodology was tested by the help of survey forms which were circulated in Telecom industry professionals in this relevant field. The survey forms were populated with survey questionnaire previously used in similar documented researches. The retrieved data went through various tests on SPSS tool to conclude the research results as mentioned in subsequent sections. 


\section{RESEARCH METHODOLOGY}

For the matter of examining the assumptions generated in preceding chapter, a methodology for the research is presented here. In a step by step approach, all the working along with its respective relevance to study is explained. In this chapter several topics are being elucidated like research design, research instrument, explanation of variables, variable categorization, sampling technique, data collection procedure and technique for data analyses.

\section{A. Nature of Study}

Being a quantitative type of the research, statistical tests in several dimensions are employed for examining the aforementioned hypotheses. Moreover, descriptive statistics provide the much needed synopsis directing towards the performance of different variables. Whereas, verification of relationships among each other is performed by the help of correlation analysis and regression analysis. The same tests also quantify the impact of dependent and independent variables among each other. A methodology of performing survey is being employed for this study. Zikmund \& Babin have maintained that survey technique is most efficient way to gather information from respondents through questionnaire. The objective of such survey remains to determine relationship among different variables. A requirement of using primary data in the research makes survey technique the obvious choice [18]. Bell also signifies the importance of survey technique in collection of primary survey data at lower costs and higher generalization. [19]

\section{B. Research Instrument}

A close-ended survey questionnaire is being used to get responses from individuals. Close ended questionnaires enables the respondent to swiftly conclude the best option among different available options also backed by Sekaran. [20] In this research, the research instrument is further segregated in two sections. First Section namely, Section-A collect responses for demographic related statistics. Moreover, second section namely Section-B constitutes of five subsections, i.e. the independent variables manager competence, leadership, integrity and team building while the last one covers project success, which is dependent variable of the study. The success of a project was assessed using survey Likert scale given by Shenhar. [21] Manager Competence was measured using the scale adopted from the questionnaire developed by Muller \& Turner. [9] Leadership was measured on the scale by Turner. Team Building was measured on the scale by Dinsmore \& Brewin. [16] Moreover, integrity is estimated by implying ethical leadership questionnaire designed by Yukl (2010) [45]. A Likert Scale with five possible responses was employed to collect the survey answers. This Likert scale is being employed in a similar fashion as being used in previous researches from where the questionnaire is adapted completely. As a survey requirement, respondents were intrigued to reply with their level of agreement or disagreement for diverse statements. These replies could be either of the following five choices, i.e. agree, disagree, strongly disagree, strongly agree and neither agree nor disagree.

\section{Variables and Measures}

Zikmund suggests that variable could be an entity which may adopt diverse value in a totally numeral approach. [18] The common relationships and effect of different variables on others may demand categorization in either dependent or independent variables. These are explained further in detail in the subsequent sub-sections.

The Independent Variables: Independent variable can be termed as an explanatory variable used to approximate the effect on a dependent variable. Based on previously elaborated literature review and research framework; manager competency, manager leadership and team integration abilities are the independent variables of the study which may have direct impact on the dependent variable elaborated below. The second sub-section of the survey questionnaire is developed to get responses about the independent variables.

The Dependent Variables: The dependent variable is predicted or explained by its dependency on explanatory or independent variables. As previously explained, the primary research objective is to evaluate the connection of project success to manager competency, manager leadership and manager's team integration abilities. First sub-section of the questionnaire comprises of questions measuring project success.

\section{Sample and Population}

Sekaran suggests that the population is complete set in terms of individuals, specified items or listed events for any samples of study to be extracted from. [20] Total count of employees in project related departments in telecom sector of Pakistan defines this study's population. The process of choosing a portion, sector or part from the total population which is representative of the whole can be termed as sampling. For the determination of the sample size, a widely used simplified formula for proportions generated by Yamane (1967) is employed. [22]

$$
n=\frac{N}{\left(1+N \cdot e^{2}\right)}
$$

Where:

n corresponds to 'sample size"

$\mathrm{N}$ corresponds to 'Population size'

\section{$\&$ e corresponds to 'tolerance error'}

The estimated $n$ number of employees in project related departments in telecom sector of Pakistan is around 850. With a $5 \%$ tolerance error, the appropriate size for the sample is 272

As per the calculated sample size, the survey was conducted with these employees using cluster sampling technique. In this sampling strategy, complete set of population is segregated in various clusters. A purely random sample is then selected from these groups as a representation of the complete data. Later on, the components in these clusters were sampled. The objective related to cluster sampling is always to skim the count of survey forms which also reduces the costs in relation with expected accuracy. Since it was a static sampling scope, the random error ' $\mathrm{e}$ ' was also expected to be less significant when most of the deviation 
in the samples is present internally within the groups, and not between the groups. Based on ease of access and availability of employees falling in the respondent category, survey forms were distributed. As a result, a total of 350 survey forms were distributed in hard copy form to be manually filled by each respondent. However, at a return rate of $84 \%$, number of properly filled and received forms were 295. These survey forms were then formulated in to tabular form to be used for SPSS related results.

\section{DATA ANALYSIS}

Following is the deliberation of the outcomes of various tests which were run for the collected statistics and their interpretation rendering the methodology. The demographics and descriptive statistics followed by reliability statistics are covered here. Furthermore, analysis for the correlation of variables and the multiple regression and interpretation of results is done simultaneously to get them aligned as per the research objectives.

\section{A. Demographics and Descriptive Statistics of the Sample}

Based on the survey response, the average age of respondents is within 28-33 year window. This suggests that most of the respondents were not novice but in fact they were well groomed professionals. Moreover, the respondents in age bracket of $18-22$ is very low because they are mostly at the beginning of their careers. Similarly the low percentage of respondents in bracket above 40 years are professionals usually not involved in day to day project management. This category of respondents is mostly involved in decision making which involves overlooking of project management. Fig. 2 is given below showing demographic view of the data pertaining to age of respondents.

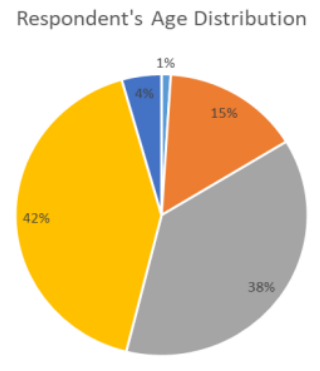

$=18-22 \cdot 23-27=28.33+34.40 \cdot$ Above

Fig. 2. Respondent's Age Distribution

Going forward towards the gender distribution, the sample of the respondents tilted slightly towards the male side; out of 295 respondents $79 \%$ are male and $21 \%$ are female. The reason for this distribution is the cultural inclination of more male professionals in this field of occupation than females. An important demographic distribution extracted through surveys is the education and job experience level of respondents. Most of the respondent's education level is at bachelors and masters level. Moreover, the job experience level showed a bell curve with most of the respondents at initial level management. As a reflection of age brackets, the job level of respondents is also mostly concentrated in two main groups i.e. initial and middle level management. Moreover, beginner and senior level management groups constitute the least percentage of survey respondents.
Respondents Education Level Distribution

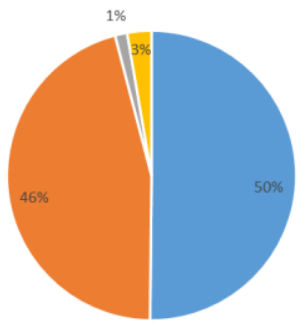

- Bachelors "Masters "Doctorate "Other

Fig. 3. Job Experience Level Distribution

\section{B. Descriptive Analysis of Variables}

The mean values of all the variables reflect a homogeneous trend. The average values of each category is between 3.8 and 3.9 which indicates that the respondents are mostly like-minded. The standard deviation for competence and project success is more than team integration and leadership which have lower deviance from standard answers.

\section{TABLE I DESCRIPTIVE ANALYSIS OF VARIABLES}

\begin{tabular}{|c|c|c|c|}
\hline Variable & N & Mean & Std Dev \\
\hline COMPETENCE & 295 & 3.86 & 0.63 \\
\hline LEADERSHIP & 295 & 3.84 & 0.32 \\
\hline TEAM BUILDING & 295 & 3.82 & 0.37 \\
\hline INTEGRITY & 295 & 3.76 & 0.59 \\
\hline PROJECT SUCCESS & 295 & 3.83 & 0.63 \\
\hline
\end{tabular}

\section{Reliability Analysis}

The output value of Cronbach Alpha displays degree of reliability amongst the diverse variables and their internal consistency. In Table 4.6, major hypotheses and respective reliabilities are being reported in the form of SPSS results. Based on this SPSS result, the conclusive value of Cronbach Alpha is 0.88 for all the variables collectively, which proves data consistency. Moreover, individual reliabilities for independent variables are produced separately through SPSS and all these results are more than 0.7 threshold. This suggests that there exists high reliability of the data. The dependent variable has reliability as 0.79 . The reason for above 0.8 alpha is because of the fact that survey respondents have been a closed group with high likelihood of similar responses.

TABLE II RELIABILITY ANALYSIS RESULT

\begin{tabular}{|c|c|}
\hline Variable & Cronbach's Alpha \\
\hline Project Success & 0.79 \\
\hline Manager Competence & 0.81 \\
\hline Leadership Skills & 0.71 \\
\hline Team Building & 0.77 \\
\hline Integrity & 0.86 \\
\hline Overall & 0.88 \\
\hline
\end{tabular}




\section{Multi-Collinearity Test}

A test of multi-collinearity is applied, in order to investigate if there exists an interrelation among the independent variables. It is vital that there must not exist any multicollinearity amongst different variables to conclude that the equation for regression is significant. By employing Variance Inflation Factor test (VIF test) or subsequent tolerance test, respective multi-collinearity is analyzed among independent variables. The VIF test depicts the deviation in terms of variance of each variable with respect to the each other. The Tolerance value is the reciprocal of VIF value for representation purposes. As a standard practice, VIF result has to be less than 5 whereas Tolerance test is to be more than 0.2 to conclude that it has no multi-collinearity.

\section{TABLE III MULTI-COLLINEARITY TEST RESULT} Coefficients $^{\mathrm{a}}$

\begin{tabular}{|l|r|r|r|r|}
\hline & & & \multicolumn{2}{|c|}{ Collinearity Statistics } \\
\cline { 5 - 6 } Model & \multicolumn{1}{c|}{$\mathrm{t}$} & Sig. & Tolerance & \multicolumn{1}{c|}{ VIF } \\
\hline 1 (Constant) & -.093 & .926 & & \\
Manager Competence & 9.009 & .000 & .351 & 2.847 \\
Leadership Skills & 1.335 & .183 & .442 & 2.261 \\
Team Building Skills & .155 & .877 & .345 & 2.896 \\
Integrity & 6.883 & .000 & .360 & 2.774 \\
\hline
\end{tabular}

a. Dependent Variable: Project Success

\section{E. Correlation Analysis}

The data analysis further requires the correlation test among the all the variables i.e. Project Success, Competency, Leadership and Team Integration abilities of Project Managers. The coefficients are reported as under.

\section{TABLE IV CORRELATION COEFFICIENTS}

\begin{tabular}{|c|c|c|c|c|c|c|}
\hline & \multicolumn{6}{|c|}{ Correlations } \\
\hline & & Project Success & Manager Competence & Leadership Skills & Team Building Skills & Integrity \\
\hline \multirow{5}{*}{$\begin{array}{c}\text { Pearson } \\
\text { Correlation } \\
\text { Sig. (2-tailed }\end{array}$} & \begin{tabular}{|l|} 
Project Success \\
\end{tabular} & & $.801^{\prime \prime}$ & $.484^{\prime \prime}$ & $.586^{\circ}$ & $.778^{\circ}$ \\
\hline & Manager Competence & .801 & & .462" & $.635^{\circ}$ & $.776^{\circ}$ \\
\hline & Leadership Skills & .484 & .462" & 1 & $.736^{\circ}$ & .525 \\
\hline & Team Building Skills & .586 & $.635^{\prime \prime}$ & $.736^{\circ}$ & & $.614^{\circ}$ \\
\hline & Integrity & .778 & $.776^{\circ}$ & $.525^{\prime \prime}$ & .614" & \\
\hline
\end{tabular}

These results demonstrates that a manager competence is highly and positively correlated to project success. Moreover, its value suggests that the manager competence can have high influence on project success as perceived by the respondents. Therefore 1st Hypothesis is accepted. i.e.

H1: Project Manager Competency is positively related to project success.

This result also portrays that the leadership skills of different project managers have correlated with project success. It can be inferred that leadership abilities of a manager also influence project success but not to the extent as manager's competence does. Therefore 2nd Hypothesis is accepted. i.e.

H2: Project Manager Leadership is positively related to project success

Correlation between team building and Project success is also found. This depicts that team building abilities of a project manager influence the project success more than his leadership skills but still lesser than his competence. Hence the 3rd Hypothesis is accepted. i.e.

H3: Team Integration abilities of project managers has a positive relationship to project success.

Integrity with a correlation coefficient almost equivalent to manager's competence suggest positive stimulus on project success. Therefore, the 4th Hypothesis is accepted as below.

H4: Manager Integrity influences the project success positively.

Moreover, the leadership skills and team building are also positively correlated. This suggest that a project manager having good leadership skills will also have high team building abilities. In a project both these qualities contribute towards success of the project in a positive way. Similarly, project manager's competence and team building abilities are also positively correlated. This implies that a competent project manager will have good team building abilities.

\section{F. Regression Model Reliability Analysis}

The regression analysis delivers the magnitude of effect which each of the independent variable may have on Project Success. In order to start the regression test itself, first evaluation needs to be performed whether overall model is reliable to run regression and acquire effective outcomes. Reliability scores are reported below.

\section{TABLE V RELIABILITY ANALYSIS}

\begin{tabular}{|c|c|c|c|c|}
\hline \multicolumn{5}{|c|}{ Model Summary } \\
\hline Model & $R$ & \begin{tabular}{l|} 
R Square \\
\end{tabular} & Adjusted R Square & Std. Error of the Estimate \\
\hline \begin{tabular}{|l|l|}
1 & \\
\end{tabular} & $.841^{\mathrm{a}}$ & .707 & .703 & .341 \\
\hline
\end{tabular}

Effectiveness of a model suitability is reflected by $\mathrm{R}$ Square value which is called regression coefficient which ranges between 0 and 1 . The resulted value of 0.659 reflects that the model easily explains more than $60 \%$ deviation in dependent variable due to the independent variable. The remaining of the variation other than $60 \%$ is produced by supplementary factors.

\section{TABLE VI ANOVA TEST}

\begin{tabular}{|c|c|c|c|c|c|c|}
\hline \multicolumn{7}{|c|}{ ANOVA $^{a}$} \\
\hline & & Sum of Squares & df & Mean Square & $\mathrm{F}$ & Sig. \\
\hline \multirow[t]{3}{*}{1} & Regression & 81.179 & 4 & \multirow{3}{*}{$\begin{array}{r}20.295 \\
.116\end{array}$} & \multirow[t]{3}{*}{174.739} & \multirow[t]{3}{*}{$.000^{6}$} \\
\hline & Residual & 33.682 & 290 & & & \\
\hline & Total & 114.861 & 294 & & & \\
\hline
\end{tabular}

a. Dependent Variable: Project Success

b. Predictors: (Constant), Integrity, Leadership Skills, Manager Competence, Team Building Skills

The ANOVA test depicts the F value which happens to be significant and positive. Due to the smaller value of variable $\mathrm{F}$, the overall research can be concluded as valid and significant. Moreover, the data demonstrates normal distribution referring to the $\mathrm{p}-\mathrm{p}$ plot chart. The same is reflected in histogram figure. Moreover, the bell curve in histogram plot determines a normal distribution for the data. 


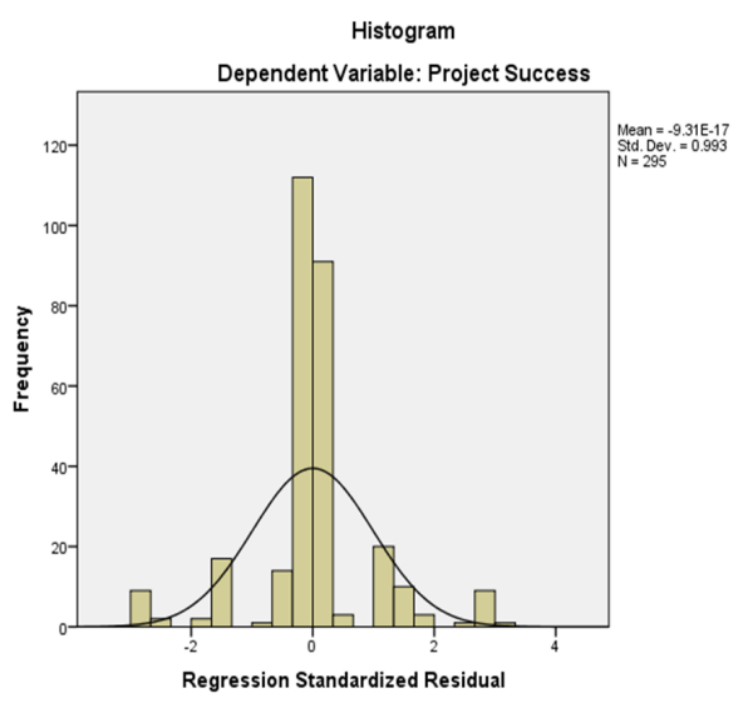

Fig. 4. Histogram of the dependent variable

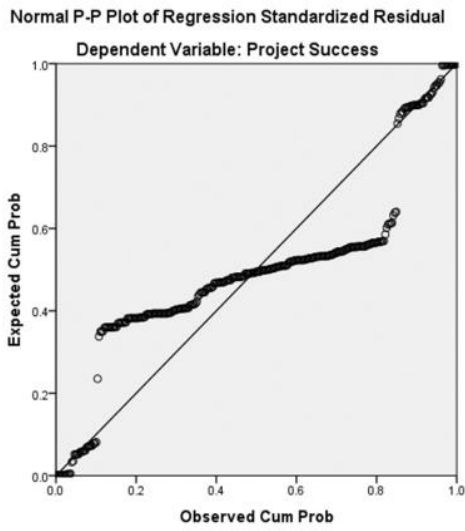

Fig. 5. Normal Plot of the Regression Residual

\section{G. Regression Analysis}

Based on the suitable results shown in reliability statistics we move on to the actual regression analysis now. Below results for multiple regression is evaluated using SPSS 20.0.

TABLE VII ANOVA TEST

Coefficients $^{\mathrm{a}}$

\begin{tabular}{|c|c|c|c|c|c|}
\hline \multirow[b]{2}{*}{ Model } & \multicolumn{2}{|c|}{ Coefficients } & \multirow{2}{*}{$\frac{\text { Standardized Coefficients }}{\text { Beta }}$} & \multirow[b]{2}{*}{$t$} & \multirow[b]{2}{*}{ Sig. } \\
\hline & $B$ & Std. Error & & & \\
\hline 1 (Constant) & -.023 & .246 & & -.093 & .926 \\
\hline Manager Competence & .482 & .054 & $.4 \varepsilon$ & 9.009 & .000 \\
\hline Leadership Skills & .126 & .095 & .06 & 1.335 & .183 \\
\hline Team Building Skills & .014 & .091 & .0 & .155 & .877 \\
\hline Integrity & .387 & .056 & .36 & 6.883 & .000 \\
\hline
\end{tabular}

a. Dependent Variable: Project Success

The regression equation is as follows

$\mathrm{SCSS}=\alpha+\beta 1 \mathrm{COMP}+\beta 2 \mathrm{LEAD}+\beta 3 \mathrm{TEAM}+\beta 4 \mathrm{INTG}+\varepsilon$

Where:

COMP is Manager's Competence

LEAD is Managers Leadership abilities

TEAM is Manager's Team Building abilities

INTG is Manager's Integrity traits
SCSS is Project Success

After inserting these coefficients from regression table to the regression equation, following is the final form of regression equation.

$$
\begin{aligned}
\mathrm{SCSS}= & -0.23+0.482 \mathrm{COMP}+0.126 \mathrm{LEAD} \\
& +0.014 \mathrm{TEAM}+0.387 \mathrm{INTG}+\varepsilon
\end{aligned}
$$

The positive coefficients on competence, leadership, integrity and team building skills of project manager indicate that with increased level of manager competence, leadership and team building skills may also increase project success. However, the effect of Manager's competence and Integrity are higher and more significant. Whereas the negative constant of this equation indicates that in the absence of competence, leadership and team building expertise of a PM can adversely impact the project success. Variations in beta coefficients imply that weight of each and every independent variable can be dissimilar. Correlation analysis also suggested that all three independent variables have significant relation to Project Success. The results are mostly in agreement and harmony with respect to the former studies in similar areas. In other words, project manager's competence, leadership skills, integrity traits and team integration abilities lead to project success. Hence, the 5th hypothesis is accepted, i.e.

H5: Success of Projects in Telecom Industry of Pakistan are affected by Competency, Leadership, Integrity and Team Integration abilities of Project Managers.

\section{DISCUSSION AND CONCLUSION}

\section{A. Project Success and Role of Project Manager}

The telecom sector of Pakistan is one of the most prosperous and flourishing functions of economy. Over the last two decades, this sector alone have contributed towards the uplifting of hundreds of thousands of households in urban and rural Pakistan. The higher rate of tele-density as equated with neighboring countries in the same region is one of the prime indicators for the success of this industry. However, all this progress in the field of telecom owes its success to heavy investments in latest technologies deployed throughout the breadth and width of the country. These investments are guaranteed to be deployed uniformly and promptly with the help of dedicated project management teams that work tirelessly for achieving project organizational objectives and retain a reasonable position for their respective organizations. Each project success have its direct impact on commercial growth of that organization alongside many other related businesses.

The project manager's role in order to steer the overall project to success is very important. Some important expertise in a project manager commonly have direct impact over the project success. This study have endeavored to explore the effects of project manager's competency profile, leadership style and team building abilities on the project success within the telecom industry of Pakistan. It also indicates the extent to which these abilities have their respective impact on project success. 


\section{B. Demographic Background of the Respondents}

The demographics of the project are reflective of the actual telecom industry in Pakistan. The respondents were predominantly male due to poor gender distribution similar to other factions of working class in corporate sector. The age distribution is largely centralized to mid-career professionals. The reason for that could be the stagnancy in the telecom sector which resulted due to slow economic growth and slow pace of introduction of new technologies. Mostly, fresh graduates are not able to secure jobs in project management departments in big telecom organizations. This is so because the skilled workforce in project management factions is generally preferred by employers.

If we look at the education level of respondents, more than $80 \%$ have at least undergraduate qualifications with almost half of them also having a Graduate degree. As depicted in Table 4.3, the results also suggest that there is a minor percentage of respondents with Post Graduate qualifications.

Moving forward to the actual organizations of these respondents, it can be explained that most of the respondents are part of established telecom service providers in Pakistan. These organizations are PTCL, Ufone, Mobilink, Telenor and Zong. Apart from telecom service providers, a large sum of employees are also working with telecom vendors. The data is representation of these vendors as well including Huawei, Nokia and ZTE.

\section{Descriptive Analysis}

The descriptive analysis reveals that the employees in Telecom sector of Pakistan have considered manager competence as the single most influential trait in a project manager for delivering an effective project. Moreover, the absence of this trait according to the survey results, will negatively impose a huge impact on the respective project success. This acts as an indicator that most of the employees targeted in the survey have seen such situations and have inferred that manager competence is an important requirement in the deliverable of overall successful project. The assumption in the project beginning that the project success can be highly reliant on various competences of project manager stands true which is also supported by the research outcome. Moreover, the project management notion suggests a horizontal relationship between managing leadership and the project success. A wide range of capabilities are essential in diverse projects and highly dependent considering their levels of intricacies. Due to different characteristics of project managers, same influence is reflected upon the success of most projects. Hence it is concluded that by bearing in mind the exact project type, a project manager should be wisely selected in order to deliver a healthy and positive project outcome.

Similar results associated to the leadership skills of project managers revealed that the influence of leadership traits in project manager are positive on the project success. This impact however is lower than that of manager competence. The underlying reason for that can be the fact that most projects are operated on a certain time frame. The project delivery somewhat limits the evaluation of everyday employees in terms of leadership skills. The leadership skills are more visible to subordinates when they have the same project manager for a much extended period. This is generally not the case for most of the projects in Pakistan. Moreover, if we look at the demographics associated with the survey respondents, it can be deduced that almost half of the subset are at the career level of being a leader themselves. So there can be an understanding perspective which delivered the evaluated results. Hence, the leadership skills influence on project success is positive but limited due to environment and project types. It is therefore recommended that there should be special training programs devised to improve the leadership skills of project managers.

Team building abilities of a manager have shown positive influence on project success. The reported influence is more than that of leadership skills but still lesser than the competence. The research literature indicated that the team building concept develops possibly, an influential mediation for enhancing the organizational performance through employee development. As a pre-requisite, the conditions of specific working group and administrative context are apposite. (Dyer[26]; Liebowitz\& De Meuse[25]; Adair[27]; Woodcock[28]) Team building abilities of a manager are associated with the people management skills of any manager. In a tough routine guided by the strict project deliverable timelines require that the teams are manages with special attention. The increase in trust, team-spirit and the eminence of data dissipation among varying team-members also enables team to further develop several competencies. These competencies include development of self-imposing and self-rectifying project controls, focus on problem solving, make individual and group commitment and effective decision-making processes. These factors relate to the overall capacity of a project manager to effectively deliver the project. The research proves again that these abilities have a positive contribution towards project success. As an important research recommendation, it is suggested that the team building activities should be encourages on organizational level to harvest the benefits on project success.

The integrity traits of a project manager have surfaced as an important influencer on project success. Results suggest that influence of integrity stands at second number after manager competence. Ethical behavior can be observed in project managers when they intend to support factors which are morally right. Resultantly, by doing so the project managers are dispersing consciousness about the ethical conduct and honesty. [46] In earlier researches, it was suggested that projects must be established on concise and genuine objectives and on realistic measures for success of projects that supports to get the stakeholders trust. As a result, this can help lead to achieve improved project success. [47] Geoghegan and Dulewicz (2008) suggested that the trait of leadership related to efficient management of resources, empowerment and employee motivation is found to have an encouraging relationship with project success. Therefore, principled leaders are also categorized by the same characteristics. [48]

Mean value of a project success indicates that a significant number of employees related to telecom sector are well aware of the project success criterion. This also indicates that these professionals are aware of the benefits which this success may bring to their respective organizations. The 
results show a positive sign about the overall consciousness of the employees and reflects their professionalism. The actions that may evaluate the success or failure in any particular defined project are commonly regarded as success criteria. Moreover, the success-factors are the aspects of a project management which uses different methodologies to lead for a project success. One of the most pertinent and significant findings of this research implies that in the absence of competence, leadership and team building skills of project manager, there can be an adverse effect on the project success. Special attention must be given to all three independent variables so as to improve the project success rate in Telecom sector of Pakistan. These steps may include the training of aspiring project managers equipping them with required soft skills. The same training routine should be imposed on employees already working in the management group.

\section{Impact Analysis}

The impact analysis using the regression tests indicates that competence, leadership and team building skills of project manager affect the engineering professionals to effectively deliver project success. It can also be said that these are the contributing factors in shaping the future of Telecom Industry and hence must be taken very seriously while determining the objectives of a workforce for an organization. The Human Resource Departments in these organizations and top level executives should all devise a comprehensive plan to transform the existing workforce into a well versed professional ready to provide a challenging deliverable of project success

\section{E. Value Addition in Comparison with Past Researches}

Previous researches in this domain also suggested that a certain level of relation between success of a project and project manager's competence existed positively. Similar research also concluded that there happens a positive connection between success of a project and leadership traits in respective project managers. Both these conclusions have not being specific to the telecom industry in Pakistan. Moreover, these studies also have not included a new critical variable, Team Building abilities of Project managers. This additional variable, along with the conclusions drawn for specifically Telecom Industry in Pakistan is novel to this research. The value addition by concentrating the research to these parameters have provided much needed direction for the telecom organizations. As a research conclusion, it suggests that in the absence of competence, leadership and team building skills of project manager, there can be a negative impact on success of the project. Hence, the grooming of project managers in Telecom Industry should be considered as a serious requirement. Technical trainings along with improvement of social skills of a project manager will have a far reaching positive influence on the Telecom Industry in Pakistan and elsewhere.

\section{F. Limitations of the Study}

Due to the cross sectional nature and since the data is collected for single time only the results of the research are limited. Moreover, the data is collected only from within
Pakistan and may not completely reflect the perception of the engineering professionals of other regional countries.

\section{G. Future Course of Research}

This research has the prospective of developing into a comparative study on various new industries such as Information Technology and Product Manufacturing. Furthermore, the construction industry can also be explored in a similar pattern as it is one of the growing and demanding industries with respect to Project Management principles. Moreover, the number of independent variables can be explored in details for future course of research.

\section{REFERENCES}

[1] Belassi, W., and Turkel, O. I., (1996),"A new framework for determining critical success/failure factors in projects". International Journal of Project Management, Vol. 14, No. 3, pp. 141 - 151

[2] Westerveld, E. (2003), "The project excellence model: linking success criteria and critical success factors". International Journal of Project Management. Vol. 21, Pp. 411-418.

[3] Cooke-Davies, T. (2002). The "real" success factors on projects International journal of project management, 20(3), 185-190.

[4] Crawford, L. (2005). Senior management perceptions of project management competence. International journal of project management, 23(1), 7-16.

[5] Baccarini, D. (1999),'Professional project management: a shift towards learning and a knowledge creating structure", International Journal of Project Management, Vol. 30 No. 4, pp. 25-32.

[6] Ejaz, N., Hussain, J., Shabbir, F., Shamim, M. A., Naeem, U. A., Tahir, M. F., Ahmad, N. \& Farooq, Q. U. (2013). "Assessment of most critical success factors for mega projects in Pakistan". Life Science Journal 2013;10 (10s):255-261 (ISSN:1097-8135). http://www.lifesciencesite.com. 41

[7] Zwikael, Ofer and Globerson, S., (2006), "From Critical Success factors to Critical success processes". International Journal of Production Research, Vol. 44, No. 17, 1 September, pp. 3433 3449.

[8] Gokhale, D. (2005). "Project management competency mapping". PMI Global Congress Proceedings, Singapore.

[9] Muller, R. \& Turner, J. R. (2007). "Matching the project manager's leadership style to project type". International Journal of Project Management, 25 (2007) 21-32.

[10] Bakhsheshi, A. F. \& Nejad, S. R. (2011). "Impact of project managers' personalities on project success in four types of project", (2011) IACSIT Press, Singapore.

[11] Barna, L. (2013). "Assessing the importance of project management soft competencies in an IT and telecommunication company". Club of Economics in Miskolc' TMP Vol. 9., Nr. 1., pp. 17-21.

[12] IPMA “Competence Baseline". Version 3.0. IPMA, Netherlands.

[13] Arain, F. M. \& Tipu, S. A. A. (2009) "Status of project management education in Pakistan". Educational Research and Review Vol. 4 (4), pp. 148-155, April, 2009.

[14] Cartwright, Chris (2007), Project management competence development framework, Project Management Institute.

[15] Bosch-Rekveldt, M. G. C., Mooi, H. G., Verbraeck, A., Sjoer, E., Wolsing, B., \& Gulden,C. (2009). "Mapping project manager's competences to project complexity".

[16] Dinsmore, Cabanis-Brewin, Hans J. Thamhain (2006) "The AMA Handbook of Project management" Second Edition, pp. 159-163.

[17] Waqas, M. (2016) "Implications of Managers' Competence Profile and Leadership Styles While Managing Projects in Pakistan” pp. 8 15.

[18] Zikmund, W. and Babin, B. (2006) "Exploring Marketing Research" 9th ed. New York Thomson South-Western

[19] Bell, J (1996) "Doing your Research Project: A Guide for First Time Researchers in Education and Social Sciences" 3rd ed., Buckingham, Open University Press

[20] Sekaran, U. (2003) "Research Methods for Business: A Skill Building Approach" 4th ed, New York, John Wiley \& Sons 
[21] Shenhar, A. J., \& Dvir, D. (2012). "Project management research: The challenge and opportunity". Project Management Journal, 38(2): 93-99.

[22] Yamane, Taro. (1967). Statistics: An Introductory Analysis, 2nd Edition, New York: Harper and Row.

[23] Salas, E., Rozell, D., Driskell, J.D., \& Mullen, B. (1999). The effect ofteam building on performance: An integration. Small Group Research,30, 309-329.

[24] Mazany, P., Francis, S. \& Sumich, P. 1995. 'Evaluating the effectiveness of an experiential "hybrid" workshop: strategy development and team building in a manufacturing organization', Journal of Management Development, 14(1): 40- 52.

[25] De Meuse, K.P. \& Liebowitz, S.J. 1981. 'An empirical analysis of teambuilding research', Group and Organization Studies, 6(3): 357378.

[26] Dyer, W.G., (1977), Team Building: Issues and Alternatives. Addison-Welsey.

[27] Adair, J., (1986), Effective Teambuilding, Gower

[28] Woodcock, M., (1989) Team Development Manual, 2 nd Edition, Billing \& Sons

[29] Wolff, M. 1988. 'Before you try teambuilding', Research Technology Management, 31(1): 6-8.

[30] Woodman, R.W. \& Sherwood, J.J. 1980. 'The role of team development in organizational effectiveness: a critical review', Psychological Bulletin, 88: 166- 186.

[31] J. Scott Glass \& James M. Benshoff 2002 'Facilitating Group Cohesion among Adolescents through Challenge Course Experiences'

[32] N. Saraswat \& S. Khandelwal 2015 'Impact of Team Building Exercises on Team Effectiveness'

[33] Belout, A., \& Gauvreau, C. (2004). Factors affecting project success: The impact of human resource management. International Journal of Project Management, 22(1), p- 1-12.

[34] Hyvari, I. (2006), Project management effectiveness in projectoriented business organizations. International Journal of Project Management, 24, p. 216-225.
[35] Yang, L. R., Huang, C. F., \& Wu, K. S. (2011). The association among project manager's leadership style, teamwork and project success. International Journal of Project Management, 29, 258-267.

[36] Geoghegan, L., \& Dulewicz, V. (2008). Do Project Managers' Leadership Competencies Contribute to Project Success, Project Management Journal, 39, 58-67.

[37] Curran, C. S. (2009). Niedergassel B., Picker S. and Leker J., Project leadership skills in cooperative projects, Management Research News, 32, 458-468.

[38] Dulewicz, V., \& Higgs, M. J. (2003).Design of a new instrument to assess leadership dimensions and styles.Henley Working Paper Series HWP 0311. Henley-on-Thames, UK: Henley Management College.

[39] Jiang J. 2014. The Study of the relationship between Leadership Style and Project Success American Journal of Trade and Policy, 1, 51-55

[40] https://www.pta.gov.pk/en/telecom-indicators/1

[41] https://www.pta.gov.pk/en/telecom-indicators/4

[42] Padhi S. \& Mishra S. (2017). Effect of Honesty as an Ethical Value on Software Project Performance: A Grounded Theory Approach

[43] H. Kerzner Project Management: A Systems Approach to Planning, Scheduling, and Controlling. New York: John Wiley \& Sons, 2001.

[44] Trust and Integrity: Colin Bruce: Senior Manager, Operations, The World Bank, Washington, D. C., USA (2005). Leadership in Project Management (PM Network), 1, 60-61.

[45] Yukl G., Mahsud R., Hassan S. \& Prussia G. An Improved Measure of Ethical Leadership, Journal of Leadership \& Organizational Studies 2010

[46] Matloob M. Impact of Ethical Leadership on Project Success Mediating role of Employee Trust and Moderating role of Ethical Orientation. Jinnah Business Review Jan 2018, Vol. 6, No. 1, pp. 42 49

[47] Hussein, B. A., Ahmad, S. B., and Zidane, Y. J. (2015). Problems associated with defining project success. Procedia Computer Science, 64:940-947.

[48] Geoghegan, L. and Dulewicz, V. (2008). Do project managers' leadership competencies contribute to project success? Project Management Journal, 39(4):58-67. 